\title{
The boundaries and limits of community management: Lessons from the water sector in Ghana
}

\author{
Steve R. Doe and M. Sohail Khan
}

\begin{abstract}
Community management, a central part of community development, has gained wide acceptance among service intermediaries as a result of the failure of the top-down approach to community development. Governmental policy instruments therefore aim at a bottom-up approach in basic service delivery such as health care, water supply and sanitation without adequate critique of the circumstances. Operationally, the extent to which community management can be inserted into development strategies has remained elusive with mixed and often costly results. This paper critically examines community management and suggests some recommendations to help service intermediaries in the application of community management in communities larger than rural villages.
\end{abstract}

\section{Introduction}

The provision of basic services to developing countries has become an important area of concern and research since the development agenda has refocused on the urban milieu. Consequently, there is significant international interest in the provision and management of affordable basic services in developing countries. Despite all the efforts by governments and donor organizations, the global challenge is still enormous since over 1 billion people of the world's 6 billion lack access to safe drinking water whilst twice as much lack access to adequate sanitation (WHO, 2000). It is estimated that 3.4 million people in developing countries die every year from diseases due to lack of access to safe drinking water, inadequate sanitation and poor hygiene. Rapid urbanization coupled with rapid urban growth has placed extreme strain on governments in their efforts to provide basic services such as health care, water supply and sanitation. This in turn has led to widespread environmental problems and raised the incidence of morbidity and mortality among the poor and vulnerable urban 
communities. Adequate community management is therefore important to health, community development and the sustainability of communities.

In the water sector, the Earth Summits in 1992 and 2002 saw world leaders committing themselves to a comprehensive programme to bring basic services to hundreds of millions of people who lacked access by adopting Agenda 21. A guiding principle of Agenda 21 is community management of services backed by measures to strengthen local institutions in implementing basic services programmes. It is believed that only when communities are involved in decision-making will there be equitable supply of services derived from community empowerment (Rifkin, 1990; WegelinSchuringa, 1998; Laverack, 2001; Shortall and Shucksmith, 2001). Vast documentation exists on the success of community management in rural areas. However, global population trends depict rapid urbanization and formation of larger communities. The United Nations (2001) observed that whereas in 1950, 30\% of the world's population lived in urban areas, by 2000 the proportion of urban dwellers had risen to $47 \%$ and it is expected to reach $60 \%$ by 2030 . However, there is a knowledge gap on the boundaries or the extent to which community management could be applied successfully to development programmes, especially in larger communities. Can the success of community management in rural areas be replicated in larger communities? The lack of knowledge to answer these questions is costly as service intermediaries continue to promote community management as an all encompassing solution to rural and larger communities with dire consequences (Briscoe and Ferranti, 1988; Kleemeier, 1995).

The purpose of this paper is to critically examine community management of basic services in developing countries by using water supply as an example. The research for the paper draws on a review of relevant literature and concept-mapping using an analysis of case studies from Ghana by the authors. The case studies comprise a study of four communities of varying population: two rural and two small towns which have been practising community management for at least three years. The water supply systems were donor-funded so the communities have received similar training from service intermediaries.

The research methodology which forms part of the doctoral thesis of one of the authors is summarized in Table 1.

\section{Linkage between community development and community management}

Community is a word with many meanings and uses. It is customary to view community as a place in which people live (such as a village or city), or as a population group with similar characteristics (such as rural villagers 
Table 1 Summary of information available in research database

\begin{tabular}{llr}
\hline Research strategy & Target & Quantity \\
\hline Semi-structured interviews & Government/policy makers in the water sector & 10 \\
Household survey & Household heads & 344 \\
Focus group discussions & Water and sanitation committees (watsan) & 4 \\
Survey & Local private companies in the water sector & 20 \\
Observation & Water supply systems & 4 \\
Documents reviewed & & 245
\end{tabular}

or older people), or as a concern people share in common (such as religious freedom, status or women). It is also viewed in reference to social relations characterized by personal intimacy, emotional depth, social cohesion, and continuity in time (Nisbet, 1969). Checkoway (1995) however, define a community as a unit of solution in society and is a process through which people take initiative and act collectively. These definitions share the commonality of being about a group of people, with common interests who are capable of taking collective decision and action for their common good. According to Laverack (2001) the organizational aspects may act as a proxy measure for the social aspects of community empowerment. For instance, the existence of functional leadership supported by established organizational structures with the participation of community members who have demonstrated the ability to mobilize resources would indicate a community which already has strong social support elements for community empowerment. Does this apply always, irrespective of the size of the community?

The vehicle through which the collective action is exercised for the common good is community management. The standpoint of authors is pragmatic; conventional modes of infrastructure provision have failed countless millions of urban dwellers and community management offers the potential alternative solution (Cotton and Tayler, 1994). Wood (1994) defined community management as management through democratically elected representatives of the community. Wegelin-Schuringa (1998) considers community management as a form of community participation while McCommon, Warner and Yohalem (1990) distinguished community management from community participation by stating that community management is taken to mean that the beneficiaries of the service have responsibility, authority and control over the development of such services, sustainability being the point of emphasis. All the authors have used different terminology in defining community management but conceptually they are describing the same thing: a bottom-up development approach where the community members have a say in their own development; and the community assumes control - managerial, operational and maintenance 
responsibility - for the development scheme in question through their elected representatives for community development through empowerment.

This leads to the definition of community development. What is community development? In 1955, the United Nations (UN) defined community development, which was then the widely accepted expression of community participation as a 'process designed to create conditions of economic and social progress for the whole community with its active participation' (Moser, 1989). The problem identified with this definition by Abbot (1996) was that the extent to which participation can be inserted into development strategies depended on what is meant by the term and it is apparent that no clear consensus exists. Nevertheless, community development has been useful for implementing many development projects for the good of the target communities under community management. Community development is therefore operationalized through community management. The major reason for advocating community management is that the people that the projects are for should have a major say in how the scheme is constructed and managed (McCommon, Warner and Yohalem, 1990; Wood, 1994; Mayo and Craig, 1995). The theory behind community management as such aims to empower and equip communities to take control of their own development.

\section{Reflections on community management}

The literature identifies divergent views on the use of community management in general. The aim of this paper is not to cite all of them but to show the diversity.

Evans and Appleton (1993) gave some supporting reasons why the community management approach has been adopted by many governments:

- Reliability, sustainability and replicability

- Stimulus to community development

- It works

Their argument was based on a workshop organized in the Netherlands by the International Water and Sanitation Centre (IRC) which collated experiences from seven developing countries from Africa, Asia and Latin America, namely, Cameroon, Guatemala, Honduras, Indonesia, Pakistan, Uganda and Yemen. The major weakness identified with this study is that it does not mention the community settings under which community management works or its boundaries.

Among the authors who have advocated community management as a means to the empowerment of communities are Roberts and Pietsch (1996). 
In a case study carried out in Australia (Victoria) on a community care project, it was concluded that community-managed organizations can respond to aggressive instrumentalism by engaging in effective social action. Nevertheless, the study strongly suggested that for success, there needs to be a strong combination of critical ideology, close community relationships, collective decision-making, and strategic political thinking that combines structure which encourages participation as crucial ingredients. This study also does not relate the elements of successful community management to the characteristics of the towns and no mention is made of the role of the size of the communities and how this is linked to critical ideology.

Community management has not always lived up to its expectations and it faces many constraints, many of which the literature does not investigate adequately. Laryea (1994), while admitting that community management may hold the key to success in rural water supply, classifies the problems faced by community management into two broad categories:

- Internal constraints: These include constraints within the rural setting such as poverty, strong traditions, misplaced priorities and unfavourable settlement patterns.

- External constraints: These are outside the control of rural communities and include time constraints and sectoral development plans by External Support Agencies.

At the conclusion of 1990, the target for International Drinking Water and Sanitation Decade was far from reached and O'Rourke (1992) observes that community participation and management may be conducive to achieving the decade's target, but are not sustainable alternatives to strong local and national institutions in the water sector.

Many commentators have also blamed the failure of community management to deliver on a lack of feeling of ownership on the part of the community (Knudsen and Tidemand, 1989; Cotton and Tayler, 1994; Bossuyt and Laporte, 1995). Niedrum (1994) questioned the viability of community management in some communities by corroborating this with experiences from Rwanda which showed that community management failed because of differences in community and project objectives. The research fails to address what accounts for the use of community management in the operation and maintenance of water supplies in communities larger than rural communities.

The only true attempt to investigate community management for larger communities was done by Cotton and Tayler (1994). They investigated the potential of community management as a means of increasing tertiary infrastructure coverage in urban settings. They however concluded that a 
household limitation of fifty is needed for community management to be effective. Due to the small household size, they may in fact have been investigating rural communities. Evans and Appleton (1993) as well as McCommon, Warner and Yohalem (1990) recognized that there was a need for a better understanding and identification of the situations in which community management is not appropriate and should not be promoted. This research therefore contributes to a better understanding of the application of community management in communities larger than the typical rural village.

\section{A model for successful community management}

Community management works to some extent in rural villages, but extension into larger communities can produce undesirable and often costly results as depicted in the previous section. A guide for the implementation of community management will therefore go a long way in helping our understanding of the factors that contribute to successful community management and thereby avoid costly decisions.

We have identified from this research that successful community management cases have the following in common:

1 The communities are usually rural with a small population and rudimentary occupation such as farming.

2 Communities participate in the decision-making, planning and the service establishment.

3 There is a strong presence of social pressures (community cohesion) which is expressed in ownership of the development project.

From the foregoing, a model for successful community management can be specified as depicted in Figure 1.

Community characteristic, an independent variable, is an important aspect about which little is known. However, this research shows that it is important in the context of community management and development. Participation and ownership are known to contribute to sustainability of services but the linkage between the two is poorly understood. Our research shows that participation and ownership are dependent on the community characteristic. Participation generates ownership and ownership ensures participation. The model is applied to the case study in Ghana.

\section{Characteristics of community}

The important community characteristics of interest to community management which were isolated by our research are: 


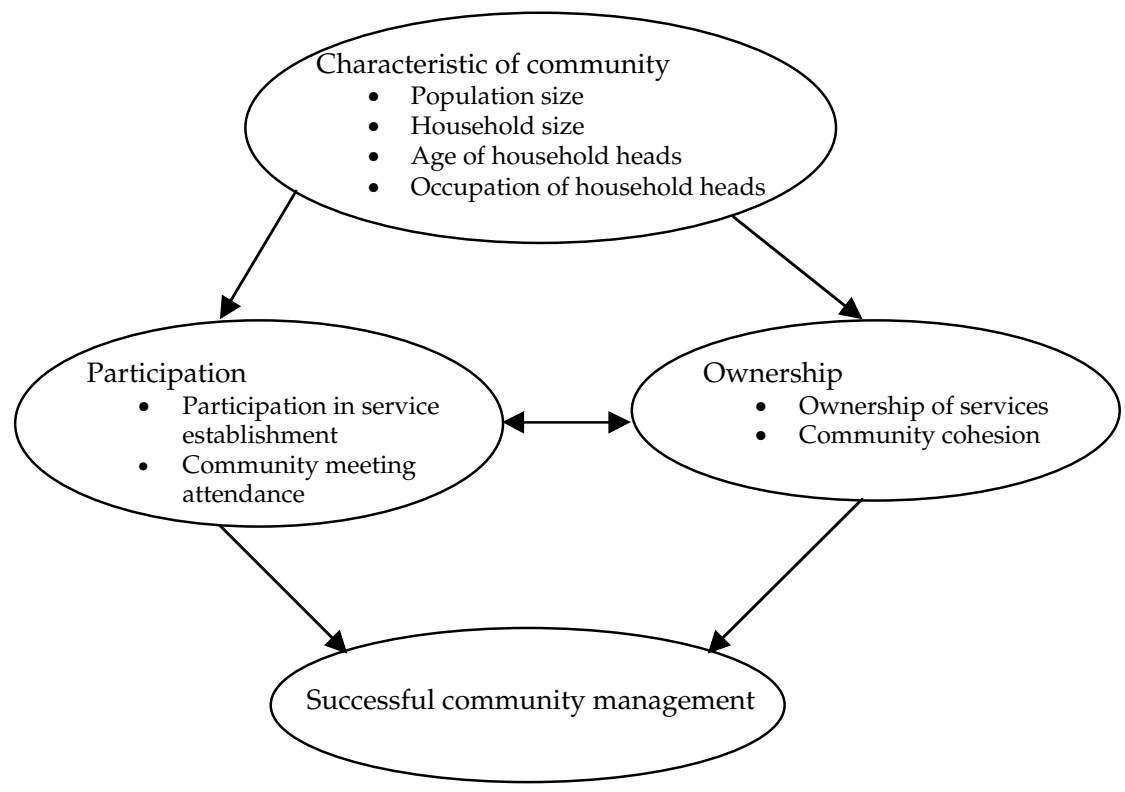

Figure 1 Components of successful community management

- Population size

- Household size

- Age of household heads

- Occupation of household heads

Population size: Population size is by far the most important and readily measurable variable. The case study in Ghana found out that, communities with populations in the neighbourhood of 1000 or less than 3000 show better community management of the development project as opposed to larger ones with population in the tens of thousands.

Household size: Smaller household sizes, especially single-family households, showed more homogeneity which fostered cohesion which is translated into participation at the community level, which in turn supported community management and development. This was absent in the larger communities.

Age of household heads: Communities with predominantly older household heads which have mature children, most of whom have left home, were found to have more time to devote to community development. Community development was therefore more successful in the smaller communities (rural villages) which had older household heads.

Occupation of household heads: Communities with a predominantly farming population were found to have more time which they devoted to 
community development. Furthermore, farming communities have communal days (taboo days) set aside for communal work for community development.

\section{Participation in the decision-making, planning and the service establishment}

The terms 'participation' or 'participatory development' are sometimes ambiguously used. They are used to describe quite different forms and intensities of involvement - from asking the target group to participate in certain activities with their labour, time and money; to informing the target group of decisions made by outsiders on their circumstances; to extracting information from them without giving them a say in decision-making; to finally basically leaving everything to the target group with a minimum of external involvement apart from maybe the provision of funds. The definition can take on radically different forms, on a continuum from spontaneous to coerced, or from active to passive (Khan and Stewart, 1994).

The Danish Development Agency has an apt definition: 'Participation is a process, through which stakeholders influence and share control over project initiatives and the decisions and resources, which affect them' (Danced, 1998).

Aryeetey (1996) was of the opinion that in the discussion of the concept of participation, it is often a question of attitude towards the stakeholders and the tasks to be carried out than a question of tools and techniques. It must however be noted that both attitude and tools are needed in a participatory process. Many of the issues that complicate the practice of community participation can be linked to a certain degree of ambiguity in the conception and expectations held by development workers as well as the communities involved. Participation must, however, not be employed for its sake. It must have as its end goal empowerment because as Laverack (2001) puts it 'empowerment has the objective to bring about social and political change' but participation alone in itself may not.

One of the underlying factors that was found to contribute to the success of community management is participation by the locals or the communities in the development projects themselves. Participation in the service establishment and attendance at meetings were used as proxies in the Ghana case study to determine the level of participation of the target group. The underlying premise is that for community management to work, the target group or community must be involved in the planning, decisionmaking and contribution of money/labour. If nothing at all, this process serves the useful purpose of bringing the people together to think about their own development. Furthermore, in order for community management 
to be sustainable after the projects that established them have ceased, community members must take an active part in issues concerning the water supply (Rifkin, 1990). The most obvious proxy to use is attendance at water supply meetings where issues related to the development project are discussed and appropriate actions taken. The results from Ghana confirmed that a positive relationship exists between the success of community management and participation by the target group.

\section{Strong sense of ownership and presence of social pressures}

Many authors have blamed the failure of community management to deliver on a lack of feeling of ownership on the part of the community (Knudsen and Tidemand, 1989; Cotton and Tayler, 1994; Niedrum, 1994; Bossuyt and Laporte, 1995). What is ownership and to what extent does a sense of ownership influence the success of community management? In the case study in Ghana, respondents were asked who they think owned the water supply systems in their respective towns as a proxy for sense of ownership. Psychological sense of ownership was found to be much higher in the smaller communities. To these communities, ownership meant no more than psychological sense of ownership which was translated positively into good community development: the smaller communities which showed a much higher sense of ownership also managed their water supply systems better than the larger communities.

Management institutions (e.g. community management) are property rights regimes which exist within a particular social context, reflecting the different understandings of human resource interrelationships, different cognitive realities of different social groups (Usher, 1983; MacPherson, 1989; Bromley 1991). It has been said that 'the difference between Indians and Europeans was not that one had property and the other had none; rather that, it was that they loved property differently (Cronon, 1983). Howeve, differences in values and understandings, the way property is 'loved' and used are found within and between other social groups as well (Ebbin, 1998). An example is the Ghana case where the smaller communities, as a result of better community education, 'love' the community water supply more because they think they own it unlike those in larger towns. This 'love' of property was translated into better management of the water supplies.

\section{Conclusion - implications for community development}

This paper aims to investigate the boundaries and limits of community management in basic service delivery by a case study of the water sector in 
Ghana. The following useful lessons for the planning of community management can be identified:

- Community management is useful for community development but one size does not fit all - community management is not equally applicable in all community settings. Recognition of this fact is an important step toward developing successful community development projects using alternative approaches.

- Size matters - The size of the community for community management is important. Communities in the tens of thousands in population have a higher probability of failed community management than smaller ones with populations in the neighbourhood of 1,000. This is because community management becomes overtly problematic as one seeks to extend the boundary from rural to larger communities of population in the tens of thousands without first changing the underlying characteristics of the communities. However this is a difficult task as pointed out by Mazmanian and Sabatier (1983) who believe that the probability of implementation failure increases with the amount of behavioural modification required to achieve statutory objectives and that this is a function of both the number of people in the target group and the degree of change required of them.

- A different approach other than community management employing the active involvement of the communities is needed for communities larger than typical rural areas.

- Studying the characteristics of the target population should form a vital part of any policy formation and implementation for community development and empowerment.

- The interfaces at which different stakeholders physically interact are critical to promoting wider participation for community development. Studies that identify the constraints to establishing and maintaining the user-implementer relations will provide valuable lessons.

\section{Acknowledgement}

Funds for the fieldwork were made available under a DFID Kar project for which we are grateful.

Steve Doe is a Civil Engineer at West Yost Associates, USA. M. Sohail Khan is a Professor and Research Manager, WEDC, Loughborough University.

Address for correspondence: steve_doe@hotmail.com or M.Sohail@lboro.ac.uk 


\section{References}

Abbott, J. (1996) Sharing the City: Community Participation in Urban Management, Earthscan, London, UK.

Aryeetey, E. B. (1996) Transfer of Ownership in Participatory Community Development: Working out the Strategies in Ghana, DPPC New Series Discussion Papers: no. 68. University of Bradford Series, Bradford, UK.

Bossuyt, J. and Laporte, G. (1995) Combining ownership and accountability in technical cooperation, International Journal Of Technical Cooperation, 1 (1), 107-116.

Briscoe, J. and Ferranti, D. (1988) Water for Rural Communities: Helping People Help Themselves, World Bank, Washington, DC.

Bromley, D. (1991) Environment and Economy Property Rights and Public Policy, Basil Blackwell Inc., Cambridge, MA, p. 247.

Checkoway, B. (1995) Six strategies of community change, Community Development Journal, 30 (1), 2-20.

Cotton, A. P. and Tayler, W. K. (1994) Community management of urban infrastructure in developing countries, Proceedings of the Institution of Civil Engineers, Municipal Engineer, v, 103 (4), 215-224.

Cronon, W. (1983) Changes in the Land: Indians, Colonists and the Ecology of New England, Hill and Wang, New York, NY.

Danced (1998) Participation in Environmental Assistance; A reference Note, Preliminary Version, Danced, Danish Ministry of Foreign Affairs, Denmark.

Ebbin, S. (1998) 'Emerging cooperative institutions for fisheries management - equity and empowerment of indigenous peoples of Washington and Alaska, A Doctoral Dissertation, Yale University Graduate School.

Evans, P. and Appleton, B., eds (1993) Community Management Today: The Role of Communities in the Management of Improved Water Supply Systems, IRC International Water and Sanitation Centre, The Hague, Netherlands.

Khan, N. and Stewart, E. (1994) Institution building and development in women's organizations: participation, ownership and autonomy, Journal of Social Studies, 63, 53-82.

Kleemeier, L. (1995) From Supply-Driven to Demand-driven of Rural Drinking Water - a Tanzanian Case Study of the Arguments of a Transition, Working Paper, Center for Development Research, Denmark.

Knudsen, H. and Tidemand, P. (1989) Debatten om folkelig deltagelse. Den nye verden 22:3. Copenhagen, Denmark.

Laryea, N. O. (1994) Challenges and prospects of community management in Ghana. In Affordable Water Supply and Sanitation. Proceedings 20th WEDC Conference, Colombo, Sri Lanka, pp. 44-45.

Laverack, G. (2001) An identification and interpretation of the organizational aspects of community empowerment, Community Development Journal, 36 (2), 134-145.

MacPherson, C. B. (1989) The meaning of property, in C. B. MacPherson, ed., Property, University of Toronto Press, Toronto, Canada, pp. 1-13.

Mayo, M. and Craig, G., eds (1995) Community Empowerment, Zed Books, London. 
Mazmanian, D. A. and Sabatier, P. A. (1983) Implementation and Public Policy, Scott, Foresman and Company, Glenview, IL.

McCommon, C., Warner, D. and Yohalem, D. (1990) Community Management of Rural Water Supply and Sanitation Services, The International Bank for Reconstruction and Development/The World Bank, Washington, DC.

Moser, C. (1989) Community participation in urban projects in the third world, Progress in Planning, 32 (2), 81.

Niedrum, S. (1994) Community Management - Lessons from Rwanda, Affordable Water Supply and Sanitation. Proceedings 20th WEDC Conference, Colombo, Sri Lanka, pp. 52-54.

Nisbet, R. (1969) The Quest for Community, Oxford University Press, New York, NY.

O'Rourke, E. (1992) The international drinking water and sanitation decade: dogmatic means to a debatable end. Water Science and Technology, 26 (78), 1929-1939.

Rifkin, S. B. (1990) Community Participation in Childhood Health/Family Planning Programmes, World Health Organization, Geneva, Switzerland.

Shortall, S. and Schucksmith, M. (2001) Rural development in practice: Issues arising in Scotland and Northern Ireland, Community Development Journal, 36 (2), 122-133.

United Nations (2001) Population, Environment and Development, Department of Economic and Social Affairs, Population Division, United Nations, New York, NY.

Usser, P. (1983) Property rights: the basis of wildlife management in National and Regional Interest in the North, Third National Workshop on People, Resources, and the Environment North of 60 degrees, Canadian Arctic Resources Committee, 389-415.

Wegelin-Schuringa, M. (1998) Community Management Models for Small Scale Water Supply Systems, Paper for discussion in workshop on public-private partnerships in service provision for community managed water supply schemes, held in Kakamega, Kenya, 7-10 December.

Wood, M. (1994) Community management of rural water supplies, Waterlines, 12 (3), 6-9.

Roberts, R. and Pietsch, J. (1996) Community management and social action: Politicisation or parochialism? Community Development Journal, 31 (2), 143-152.

WHO (2000) Global Water Supply and Sanitation Assessment 2000 Report, World Health Organization, Geneva, Switzerland. 